PREPARED FOR THE U.S. DEPARTMENT OF ENERGY, UNDER CONTRACT DE-AC02-76CH03073

PPPL-3968

PPPL-3968

UC-70

Benchmarking Nonlinear Turbulence Simulations on Alcator C-Mod

by

M.H. Redi, C.L. Fiore, W. Dorland, M.J. Greenwald, G.W. Hammett, K. Hill, D. McCune, D.R. Mikkelsen,

G. Rewoldt, and J.E. Rice

June 2004

NM|

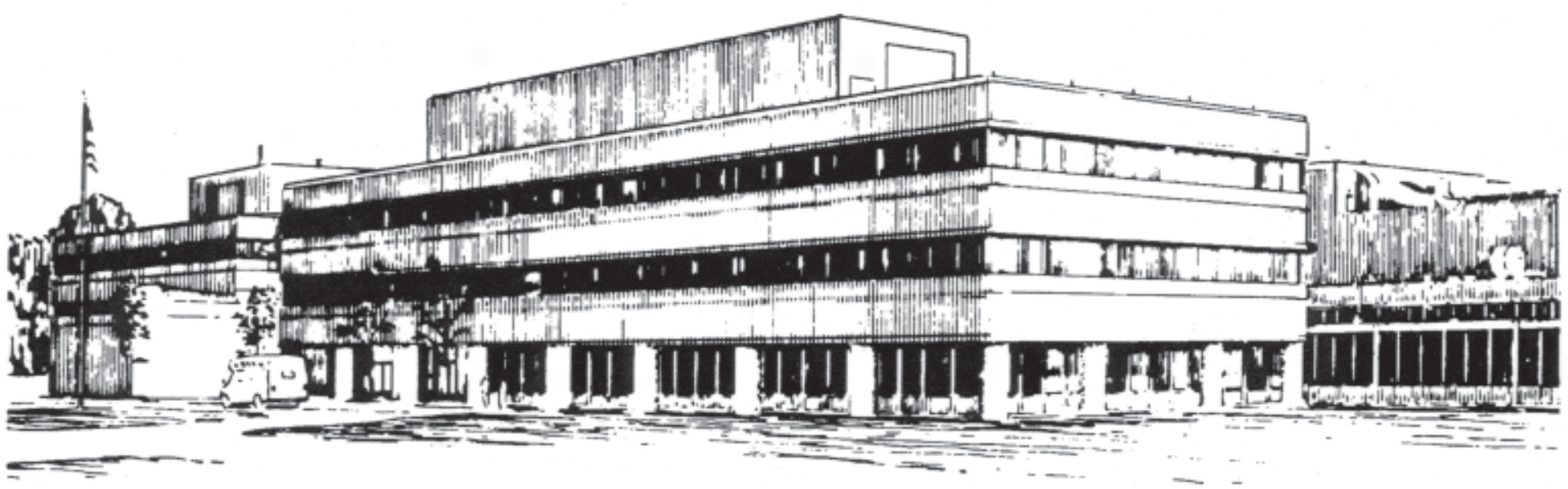

PRINCETON PLASMA PHYSICS LABORATORY PRINCETON UNIVERSITY, PRINCETON, NEW JERSEY 


\section{PPPL Reports Disclaimer}

This report was prepared as an account of work sponsored by an agency of the United States Government. Neither the United States Government nor any agency thereof, nor any of their employees, makes any warranty, express or implied, or assumes any legal liability or responsibility for the accuracy, completeness, or usefulness of any information, apparatus, product, or process disclosed, or represents that its use would not infringe privately owned rights. Reference herein to any specific commercial product, process, or service by trade name, trademark, manufacturer, or otherwise, does not necessarily constitute or imply its endorsement, recommendation, or favoring by the United States Government or any agency thereof. The views and opinions of authors expressed herein do not necessarily state or reflect those of the United States Government or any agency thereof.

\section{Availability}

This report is posted on the U.S. Department of Energy's Princeton Plasma Physics Laboratory Publications and Reports web site in Fiscal Year 2004. The home page for PPPL Reports and Publications is: http://www.pppl.gov/pub_report/

DOE and DOE Contractors can obtain copies of this report from:

U.S. Department of Energy

Office of Scientific and Technical Information

DOE Technical Information Services (DTIS)

P.O. Box 62

Oak Ridge, TN 37831

Telephone: (865) 576-8401

Fax: (865) 576-5728

Email: reports@adonis.osti.gov

This report is available to the general public from:

National Technical Information Service

U.S. Department of Commerce

5285 Port Royal Road

Springfield, VA 22161

Telephone: $1-800-553-6847$ or

(703) $605-6000$

Fax: (703) 321-8547

Internet: http://www.ntis.gov/ordering.htm 


\title{
Benchmarking Nonlinear Turbulence Simulations on Alcator C-Mod
}

\author{
M. H. Redi ${ }^{1}$, C. L. Fiore ${ }^{2}$, W. Dorland ${ }^{3}$, M. J. Greenwald ${ }^{2}$, G. W. Hammett ${ }^{1}$, K. Hill ${ }^{1}$, \\ D. McCune ${ }^{1}$, D. R. Mikkelsen ${ }^{1}$, G. Rewoldt ${ }^{1}$, J. E. Rice ${ }^{2}$ \\ ${ }^{1}$ Princeton Plasma Physics Laboratory, Princeton University, Princeton, NJ 08540 USA \\ ${ }^{2}$ Plasma Science Fusion Center, MIT, Cambridge, MA 02139 USA \\ ${ }^{3}$ University of Maryland, College Park, MD 20742 USA
}

Linear simulations of plasma microturbulence are used with recent radial profiles of toroidal velocity[1] from similar plasmas to consider nonlinear microturbulence simulations and observed transport analysis on Alcator C-Mod[2]. We focus on internal transport barrier (ITB) formation in fully equilibrated H-mode plasmas with nearly flat velocity profiles. Velocity profile data, transport analysis and linear growth rates are combined to integrate data and simulation and explore the effects of toroidal velocity on benchmarking simulations. Areas of interest for future nonlinear simulations are identified. A good gyrokinetic benchmark is found in the plasma core, without extensive nonlinear simulations.

RF-heated C-Mod H-mode experiments [3,4], which exhibit an ITB, have been studied with the massively parallel code GS2 [5] towards validation of gyrokinetic microturbulence models. New, linear, gyrokinetic calculations are reported and discussed in connection with transport analysis near the ITB trigger time of shot \#1001220016 (Fig. 1).

\section{Linear gyrokinetic simulations of ITG/TEM and ETG drift modes}

Earlier work [6] has been recomputed and verified using TRXPL software, which produces input files for GS2 from TRANSP analysis. As was found from the earlier simulations, the linear gyrokinetic simulations generally support the picture of ion/electron temperature gradient (ITG/ETG) microturbulence driving high $\square_{i} / \square_{e}$ and that stable ITG correlates with reduced particle transport and improved $\square_{i}$ on $\mathrm{C}$-Mod. Only radii at $r / a=0.25$, 0.45 and 0.65 are examined. No strongly growing modes are found linearly unstable in the plasma core. In the plasma core weakly unstable ITG range drift modes occur for simulations of five $2 \square$ field periods along the field line, but these instabilities arise from boundary conditions: $t^{i n}$ in the ITG range decreases to $0.002 \mathrm{MHz}$ when the field lines are extended to seventeen $2 \square$ field periods. Figure 2 shows ITGs destabilized at, as well as outside, the ITB region with $\left[^{\text {in }}\right.$ in laboratory units. As before [6], ETGs are strongly unstable at and outside the ITB, with $\left[^{\text {tin }}=1.9 \mathrm{MHz}\right.$ and $2.5 \mathrm{MHz}$. Initial nonlinear calculations [7] in the ITG-TEM range of wavelengths for C-Mod confirm the linear simulations, which predicted reduced 
ITG instability inside the ITB region before formation, without invoking $\boldsymbol{E} \square \boldsymbol{B}$ shear suppression of turbulence [8].

\section{Toroidal rotation suppression of microturbulence: comparison to transport analysis}

Thermal diffusivities from nonlinear microturbulence simulations outside the barrier region may be modified with the Waltz prescription [8] for $\boldsymbol{E} \boldsymbol{X \boldsymbol { B }}$ shear corrections, making use of the linear growth rates. The approximate Waltz quench rule for reduction of nonlinear ITG drift-wave diffusion by $\boldsymbol{E} \boldsymbol{X \boldsymbol { B }}$ shear compares the maximum rates of linear growth to the toroidal velocity shearing, leading to a transport reduction factor $K$ [9]. $\square=K \square_{G S 2}=\square_{G S 2}[1$ $\left.\operatorname{Min}\left\{1, G\left|\square_{x B} / \square^{i T G}{ }_{I T G}\right|\right\}\right]$, where $0.3<G<3.0$ and $\square_{x B}=R\left(B_{\square}(B) d / d r\left[V_{t o r} /\left(R_{o}+r \cos \square\right][10]\right.\right.$. This formulation neglects $v_{p o l}$ and $P \square$ A more accurate treatment is possible with the GYRO fluxtube code [11], which incorporates toroidal velocity shear along with evolving zonal flows.

We show in Fig. 3 recent velocity measurements [1] from ITB cases similar to the one simulated with GS2, In the simulated shot the core velocity at the trigger time was measured to be zero. In general, ITBs form from fully equilibrated EDA H-mode plasmas, yet the recent velocity measurements from [1] are representative of averaged plasma conditions which differ in important ways from the shot simulated. The $v(r)$ data do not show the central velocity decreasing through zero during the $\mathrm{H}$-mode to ITB phase. When $v_{\text {tor }}(0)=0$ at $1.05 \mathrm{sec}$ the central plasma pressure is $0.19 \mathrm{MPa}$ and the plasma has a fully developed ITB. Fully equilibrated EDA H-mode plasmas are seen to exhibit flat velocity profiles on C-Mod. In $\mathrm{H}$ mode near 0.9 s error bars on the toroidal velocity are typically $\pm 10 \%$ within and at the ITB region, and $\pm 20 \%$ outside. In Figure 3 are shown extrapolations of the measured core velocity data for the simulated shot. A flat profile with $v_{\text {tor }}(0)=0$ is shown at $0.25 r / a, 0.45 r / a$ and $0.65 r / a$ (open squares). Maximum velocity shearing rates are found from the blue squares, and error bars of $\pm 0.1 \times 10^{4} \mathrm{~m} / \mathrm{s}$ within and at the ITB region and $\pm 0.2 \times 10^{4} \mathrm{~m} / \mathrm{s}$ outside the ITB.

A good quantitative benchmark of gyrokinetics is possible in the core, since there $v_{t o r}$ is zero and it is likely that the velocity shear is zero. In Fig. 4 are shown $\prod_{\text {eff }}$ from transport analysis and $\square_{i}^{\text {Chang-Hinton }}$. At C-Mod's high density, $\square_{\text {eff }}$ is more accurately known than $\square_{e}$ and $\square_{i}$. Simulations are compared to $\square_{\text {eff }}$ rather than the nonequilibrium, heat pulse $\square_{\square}^{h p}[4]$. No anomalous transport is found in the core, consistent with simulations which show no strongly unstable linear microstabilities there. Gyrokinetic calculations are unlikely to yield significant nonlinearly destabilized turbulence in the core, given the flat density and temperature profiles. Self-sustained drift wave turbulence is not likely; the collisionality $\mathrm{C} \sim 10^{-3}<<1$ [12]. 
In Table I are compared the maximum linear growth rates of ITG instabilities, the $\boldsymbol{E} \boldsymbol{X} \boldsymbol{B}$ shearing rates and the Waltz quench factors, $K$ for the extrapolated open and blue square data points, based on equilibrated H-mode plasmas (Fig. 3) as discussed above. $\boldsymbol{E} \boldsymbol{X \boldsymbol { B }}$ shear suppression is subdominant except possibly in the ITB region.

Fully equilibrated, EDA H-mode plasmas on C-Mod, from which ITBs develop, exhibit nearly flat $v(r)$. At the trigger time $(0.9 \mathrm{~s})$ of the shot simulated, $v(0)$ is known to be zero, Hypothesizing $v_{t o r}(r)=0$, nonlinear flux-tube simulations could be quantitatively benchmarked against transport analysis for this experiment outside the ITB region, without the inaccuracies inherent in calculations which do not include zonal and $\boldsymbol{E} \boldsymbol{x} \boldsymbol{B}$ flow selfconsistently. $\boldsymbol{E} \boldsymbol{x} \boldsymbol{B}$ shear suppression may be important in benchmarking the gyrokinetic model against experiment in the ITB region. While linear simulations provide a good model benchmark in the plasma core, nonlinear ITG and ETG simulations are still essential for experimental validation of the gyrokinetic drift wave model at and outside the ITB.

*Supported by USDoE contract No. DE-AC02-76CH03073

[1] J. E. Rice et al. Nuclear Fusion 43 (2003) 781.

[2] I. Hutchinson, et al. Phys. Plas. 1 (2004) 1511.

[3] C. L. Fiore, et al. Phys. Plas. 11 (2004) 2480.

[4] S. J. Wukitch, et al. Phys. Plas. 9 (2002) 2149.

[5] M. Kotschenreuther, et al., Comput. Phys. Commun. 88, (1995) 128.

[6] M. H. Redi, et al, EPS, Montreux, Switzerland (2002) Paper P-1.081.

[7] M. H. Redi, et al, EPS, St. Petersburg, RU (2003) Paper P-4.94.

[8] R. E. Waltz, R. L. Dewar, X. Garbet, Phys. Plas. 5 (1998) 1784.

[9] D. Ross, Phys. Plas. 9 (2002) 177.

[10] T. S. Hahm, K. H. Burrell, Phys. Plas. 2 (1995) 1648.

[11] J. Candy, R. E. Waltz, Phys. Rev. Lett. 91, 4 (2003) 045001.

[12] B. Scott, Plasma Phys. Control. Fusion 45 (2003) A385.

Table I. $\boldsymbol{E} \boldsymbol{X} \boldsymbol{B}$ suppression factors $K(G=1)$ for open and blue squares (*), Fig. 3.

\begin{tabular}{|c|c|c|c|c|c|c|c|}
\hline$r / a$ & $D^{i n G}$ & $Z_{x B}$ & $E_{x B} *$ & 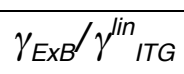 & 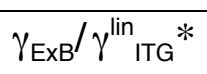 & $K$ & $K^{*}$ \\
\hline 0.25 & 0 & 0 & $0.6 \times 10^{4} / \mathrm{s}$ & 0 & -- & 1 & 1 \\
\hline 0.45 & $2.6 \times 10^{4} / \mathrm{s}$ & 0 & $1.4 \times 10^{4} / \mathrm{s}$ & 0 & 0.5 & 1 & 0.5 \\
\hline 0.65 & $13 \times 10^{4} / \mathrm{s}$ & 0 & $1.5 \times 10^{4} / \mathrm{s}$ & 0 & 0.1 & 1 & 0.9 \\
\hline
\end{tabular}




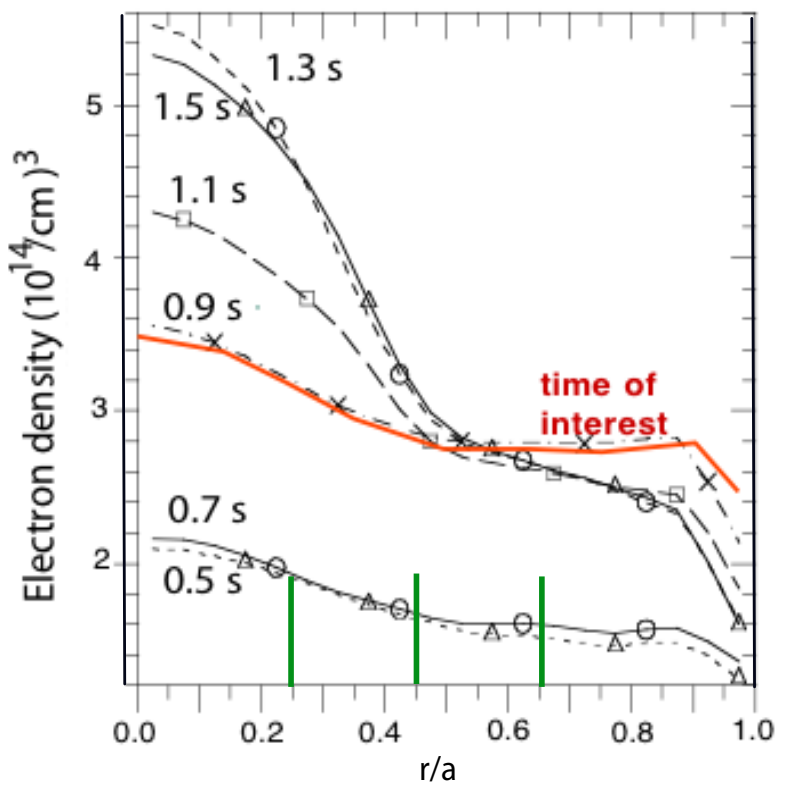

Figure 1. Evolution of electron density profile

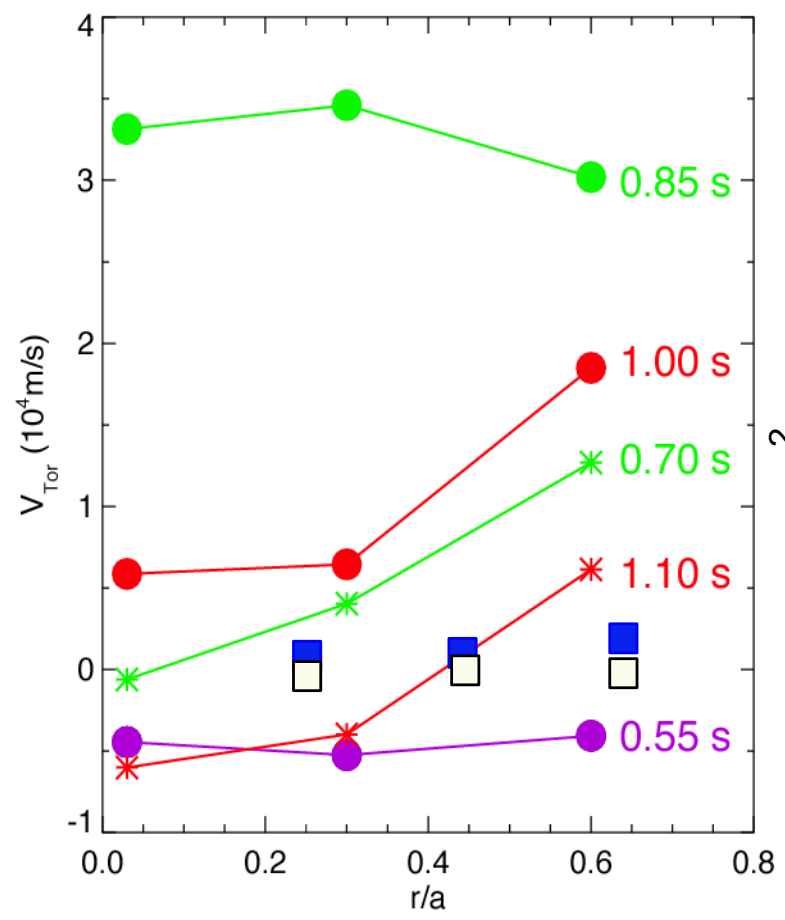

Figure 3. Toroidal velocity data, and extrapolations for shot simulated with flat $v(r)$ profile (open squares) and maximum shearing rates (blue squares).

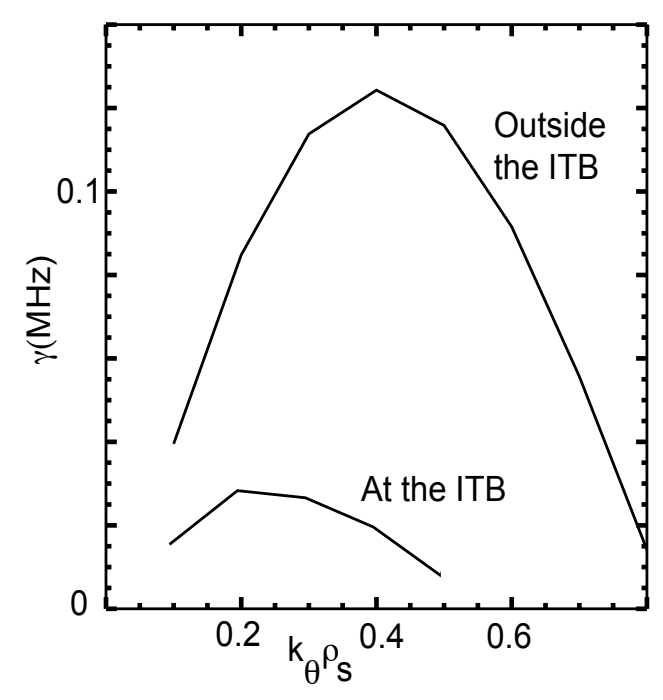

Figure 2. Linear growth rates of ITG modes at and outside ITB

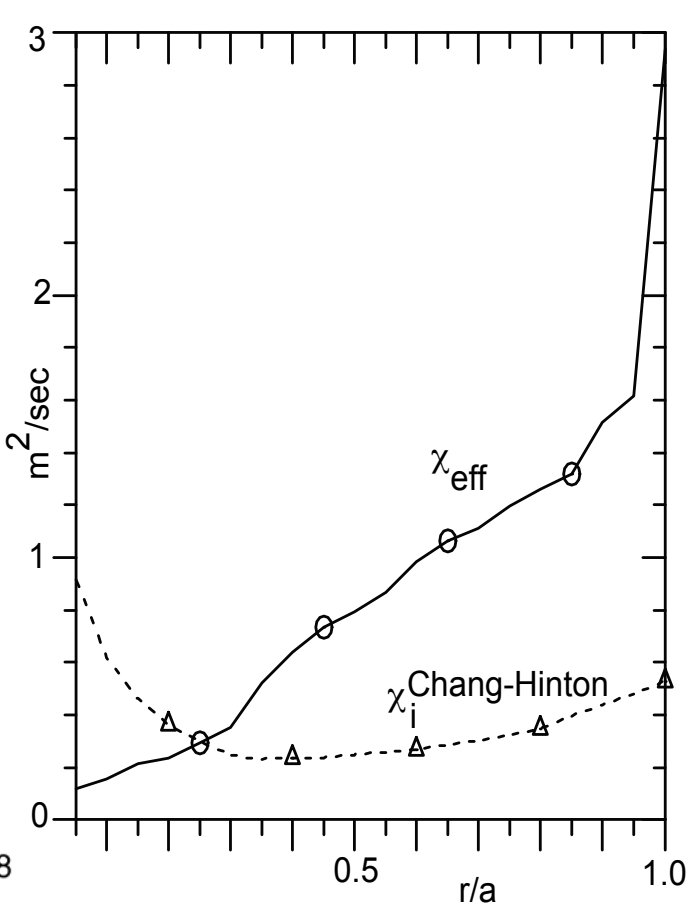

Figure 4. Radial profiles of $\square_{\text {eff }}$ and ChangHinton neoclassical ion conductivity. 


\section{External Distribution}

Plasma Research Laboratory, Australian National University, Australia

Professor I.R. Jones, Flinders University, Australia

Professor João Canalle, Instituto de Fisica DEQ/IF - UERJ, Brazil

Mr. Gerson O. Ludwig, Instituto Nacional de Pesquisas, Brazil

Dr. P.H. Sakanaka, Instituto Fisica, Brazil

The Librarian, Culham Laboratory, England

Mrs. S.A. Hutchinson, JET Library, England

Professor M.N. Bussac, Ecole Polytechnique, France

Librarian, Max-Planck-Institut für Plasmaphysik, Germany

Jolan Moldvai, Reports Library, Hungarian Academy of Sciences, Central Research Institute for Physics, Hungary

Dr. P. Kaw, Institute for Plasma Research, India

Ms. P.J. Pathak, Librarian, Institute for Plasma Research, India

Ms. Clelia De Palo, Associazione EURATOM-ENEA, Italy

Dr. G. Grosso, Instituto di Fisica del Plasma, Italy

Librarian, Naka Fusion Research Establishment, JAERI, Japan

Library, Laboratory for Complex Energy Processes, Institute for Advanced Study, Kyoto University, Japan

Research Information Center, National Institute for Fusion Science, Japan

Dr. O. Mitarai, Kyushu Tokai University, Japan

Dr. Jiangang Li, Institute of Plasma Physics, Chinese Academy of Sciences, People's Republic of China

Professor Yuping Huo, School of Physical Science and Technology, People's Republic of China

Library, Academia Sinica, Institute of Plasma Physics, People's Republic of China

Librarian, Institute of Physics, Chinese Academy of Sciences, People's Republic of China

Dr. S. Mirnov, TRINITI, Troitsk, Russian Federation, Russia

Dr. V.S. Strelkov, Kurchatov Institute, Russian Federation, Russia

Professor Peter Lukac, Katedra Fyziky Plazmy MFF UK, Mlynska dolina F-2, Komenskeho Univerzita, SK-842 15 Bratislava, Slovakia

Dr. G.S. Lee, Korea Basic Science Institute, South Korea

Institute for Plasma Research, University of Maryland, USA

Librarian, Fusion Energy Division, Oak Ridge National Laboratory, USA

Librarian, Institute of Fusion Studies, University of Texas, USA

Librarian, Magnetic Fusion Program, Lawrence Livermore National Laboratory, USA

Library, General Atomics, USA

Plasma Physics Group, Fusion Energy Research Program, University of California at San Diego, USA

Plasma Physics Library, Columbia University, USA

Alkesh Punjabi, Center for Fusion Research and Training, Hampton University, USA

Dr. W.M. Stacey, Fusion Research Center, Georgia Institute of Technology, USA

Dr. John Willis, U.S. Department of Energy, Office of Fusion Energy Sciences, USA

Mr. Paul H. Wright, Indianapolis, Indiana, USA 
The Princeton Plasma Physics Laboratory is operated by Princeton University under contract with the U.S. Department of Energy.

\author{
Information Services \\ Princeton Plasma Physics Laboratory \\ P.O. Box 451 \\ Princeton, NJ 08543
}

Phone: 609-243-2750

Fax: 609-243-2751

e-mail: pppl_info@pppl.gov

Internet Address: http://www.pppl.gov 